\title{
Data mining and pattern recognition
}

\author{
Juan C. Rocha ${ }^{1,2}$ and Stefan Daume ${ }^{1,2}$
}

${ }^{1}$ STOCKHOLM RESILIENCE CENTRE, STOCKHOLM UNIVERSITY, STOCKHOLM, SWEDEN

${ }^{2}$ BEIJER INSTITUTE OF ECOLOGICAL ECONOMICS, THE ROYAL SWEDISH ACADEMY OF SCIENCES,

STOCKHOLM, SWEDEN

\section{Key methods discussed in this chapter}

Data wrangling, clustering analysis, regression trees, neural networks, sentiment analysis, topic models

\section{Connections to other chapters}

Classical methods for statistical analysis (Chapter 18), including Bayesian networks (Chapter 16), qualitative data analysis (Chapter 19), network analysis (Chapter 23) and spatial mapping (Chapter 24), complement the methods outlined in this chapter. Data-mining products can be used for mapping ecosystem services (Chapter 31), systems scoping (Chapter 5) and participatory data collection (Chapter 8 ) in virtual environments.

\section{Introduction}

Data science is an interdisciplinary field focused on extracting knowledge and insights from a wide variety of datasets. The general purpose of data science is pattern discovery from unstructured and heterogeneous sources of data (e.g. Twitter, a government census, travel cards, remote-sensing data), through processes of data mining and machine learning. Data mining refers to the process of obtaining unstructured data, which are data collected by a variety of entities (governments, companies, society) without any control of what and how, how often, how complete, or by whom data are generated. As a result, unstructured data are often biased and incomplete, but sometimes the large amount of available data allows us to gain interesting insights into aspects of social-ecological systems (SES) that would otherwise be inaccessible. These insights are gained through a set of methods collectively referred to as machine learning (e.g. regressions, clustering, neural networks). Although these methods are rooted in statistics and carry the same assumptions (see Chapter 18), there are substantial differences in how the methods are applied to unstructured data, compared with their more typical application to structured data (i.e. data that have been collected by a researcher through a designed research process, e.g. ecological field data collection (Chapter 6) and interviews and surveys (Chapter 7)). 


\section{SUMMARY TABLE: DATA MINING AND PATTERN RECOGNITION}

\begin{tabular}{|c|c|}
\hline DISCIPLINARY BACKGROUND & KNOWLEDGE TYPE \\
\hline $\begin{array}{l}\text { The methods in this chapter are derived } \\
\text { from or have most commonly been used in: } \\
\text { Computer Science, Information Science }\end{array}$ & $\begin{array}{l}\text { The methods in this chapter are primarily } \\
\text { used to generate the following types of } \\
\text { knowledge: } \\
\text { - Descriptive } \\
\text { - Exploratory }\end{array}$ \\
\hline RESEARCH APPROACH & PURPOSE OF METHOD \\
\hline $\begin{array}{l}\text { The methods in this chapter originate } \\
\text { from or most commonly adopt the } \\
\text { following research approaches: } \\
\text { - Analytical/objective }\end{array}$ & $\begin{array}{l}\text { The most common purposes of using the } \\
\text { methods in this chapter are: } \\
\text { - Data collection/generation } \\
\text { - System understanding } \\
\text { - Policy/decision support }\end{array}$ \\
\hline TEMPORAL DIMENSION & SYSTEMIC FEATURES AND PROCESSES \\
\hline $\begin{array}{l}\text { The methods in this chapter are most } \\
\text { commonly applied to the following } \\
\text { temporal dimensions: } \\
\text { - Present (typically within the last } \\
5-10 \text { years) } \\
\text { - Recent past (post-1700s) }\end{array}$ & \multirow[t]{3}{*}{$\begin{array}{l}\text { While most methods can do many } \\
\text { things, the methods in this chapter are } \\
\text { particularly good (i.e. go-to methods) for } \\
\text { addressing the following: } \\
\text { - SES components and linkages } \\
\text { - Diversity } \\
\text { - Regime shifts }\end{array}$} \\
\hline SPATIAL DIMENSION & \\
\hline $\begin{array}{l}\text { The methods in this chapter are primarily } \\
\text { either or both: } \\
\text { - Non-spatial } \\
\text { - Explicitly spatial } \\
\text { The methods in this chapter are most } \\
\text { commonly applied at the following } \\
\text { spatial scales: } \\
\text { - Local } \\
\text { - Regional (provincial/state } \\
\text { to continental) } \\
\text { - Global } \\
\text { - Multiple places/sites around the world }\end{array}$ & \\
\hline
\end{tabular}


The field of data science can be traced back to Alan Turin, who invented the computer and created the first neural network (a machine-learning method) to crack Enigma, the secret code used by the Germans in the Second World War. He was a philosopher (logician) and mathematician (cryptographer) but founded what we know today as computer science, artificial intelligence and machine learning. Data science is agnostic in terms of discipline and data science tools are used by researchers across the sciences and humanities. In fact, the emergence of fields such as digital humanities, computational social science and citizen science highlights the lack of disciplinary borders when it comes to data science. With the advent of new types of data and tools, disciplinary divides become meaningless; what matters is the research problem at hand. The same image-recognition and classification algorithms that are used in medicine to identify and distinguish different cases of cancer, for example, can be used to classify different neighbourhoods and their social dynamics over time (Naik et al. 2017).

In this chapter we focus on how SES researchers have applied data mining and machine-learning methods to date, and provide pointers on how these tools could serve to answer novel research questions in SES science. For more information on the key assumptions of each method, see Chapter 18 on statistical analysis.

\section{SES problems and questions}

In contrast to traditional research designs, where one asks a question and then collects data to answer it, data science enables researchers to use available, unstructured data to ask SES research questions. The examples provided here cover a broad range of data types and machine-learning techniques.

- What are the system boundaries? One of the fundamental questions that any systems thinker faces is determining the boundaries of a system (Holland 2012), or distinguishing one type of system from another (see Chapter 2). Machine learning can be used to identify classes of SES through classification tasks. Clustering analysis is a method that enables this classification by detecting how many clusters there are in the data. Social-ecological systems in Ghana and Burkina Faso have been mapped using this approach (Rocha et al. 2019).

- What are the key system relationships and drivers? Machine learning can also be used for prediction in SES. To do so, it is common to split the available data into a training dataset and a validation dataset. The training phase improves the skills of an algorithm at performing a certain task, while the validation phase can be used to predict and assess how good the predictions are. This approach has been used in breakthrough studies that predict global deforestation and its drivers (Curtis et al. 2018), and reduced resilience in tropical forests (Verbesselt et al. 2016) using satellite imagery.

- What are the key social dynamics in SES? Satellite data and social data can be a powerful combination to address questions related to the social dynamics of SES. Jean et al. (2016), for example, used publicly available satellite imagery to predict poverty in data-scarce contexts such as African countries, and validated the findings using national poverty surveys. Other sources of social data, such as publicly available photographs and geotags uploaded to social media platforms (e.g. Twitter, Instagram, Flickr), have been used to quantify nature-based tourism and recreation values of protected areas (Wood et al. 2013) or valuable landscapes (Sonter et al. 2016; Van Zanten et al. 2016). Typically, recreational value data are derived through traditional social science methods such as onsite surveys and interviews. These methods are, however, not always scalable, whereas data mining enables analyses for many more people and places. 
- What are the key underlying narratives shaping SES behaviour? Text is an unstructured data type that captures the richness of narratives and meanings, but can also be overwhelming in size and demand for processing time. More papers are published every day than any researcher could possibly read, or more Tweets are broadcast than any user can access. Topic models have been used to identify the impacts of regime shifts on ecosystem services (Rocha and Wikström 2015), and infer citizen-driven reports of biodiversity observations in general and invasive species specifically (Daume, Albert, and Von Gadow 2014b; Daume 2016; Daume and Galaz 2016) (see Case study 17.1).

- How does one detect real-time changes in SES? Cities are landscapes where socialecological interactions are reshaped all the time, but studying them can be difficult in terms of scalability (i.e. being able to capture social or ecological processes at the city scale account for millions of people's preferences and choices). Data mining and machine learning have been used to assess the presence of biodiversity data in London using sound recordings (Fairbrass et al. 2018) and to quantify the physical and safety improvement of city neighbourhoods in US cities over time using Google Street View (Naik, Raskar, and Hidalgo 2016; Naik et al. 2017). These two examples have also produced online tools so that non-academic parties such as NGOs, municipal governments or citizens may explore their city's biodiversity (londonsounds.org; batslondon.com) or safety scores (streetscore.media.mit.edu).

\section{Brief description of key methods}

Data mining and pattern recognition relate to two main aspects of working with large datasets: acquiring the data, and analysing them in a variety of ways to detect patterns. The type of analysis will depend on the nature of the data: qualitative or quantitative analyses, time series versus spatial analyses, or supervised learning (human-guided) versus unsupervised (fully automated) analyses. Table 17.1 provides a summary of commonly used data-mining and pattern-recognition methods in SES research. While an in-depth review of each of the methods falls beyond the scope of this chapter, we mention resources where the reader can learn more.

Many applications of pattern recognition to different SES use large volumes of unstructured data that typically need to be harvested, cleaned and transformed to render them useful. Whereas 'mining' refers to getting the data, 'wrangling' refers to the pre-processing steps that are necessary before analysis. This implies automation and techniques that require the mastery of data-processing tools or programming languages like $\mathrm{R}$ or Python, and the interaction with application programming interfaces (APIs).

Cluster analysis is particularly useful to identify patterns that can help define system boundaries. In the context of the global consequences of land-use change, for example, Foley et al. (2005) proposed that landscapes can be classified by the sets of ecosystem services they provide. Other classifications of land use at the global scale include anthromes (Ellis and Ramankutty 2008; Ellis et al. 2010) and general land-use archetypes (Václavík et al. 2013; Ropero, Aguilera, and Rumí 2015; Surendran et al. 2016). Regression trees are helpful for identifying key relationships and drivers. Donovan et al. (2018), for example, used clustering analysis to classify five different regimes in Hawaiian coral reefs as opposed to a previous binary classification, and Jouffray et al. (2019) further investigated the underlying drivers of change for these reef communities using boosted regression trees.

Neural networks are programs (Bayesian regressions) inspired by how the brain is thought to work (Mitchell 2019). They are formed by input nodes, intermediate layers of nodes and an output node. The input nodes receive some data (a photo, video, time series) and the 
Table 17.1 Summary of key methods used in data mining and pattern recognition

\begin{tabular}{|c|c|c|}
\hline Method & Description & References \\
\hline Data wrangling & $\begin{array}{l}\text { Data wrangling is the process of cleaning data } \\
\text { that have been obtained and rendering the } \\
\text { data in a useful form. }\end{array}$ & $\begin{array}{l}\text { Key introductory texts } \\
\text { VanderPlas 2016; } \\
\text { Wickham and Grolemund 2017; } \\
\text { Wilson et al. } 2017 \\
\text { Applications to SES } \\
\text { No known applications }\end{array}$ \\
\hline Cluster analysis & $\begin{array}{l}\text { Clustering identifies groups of data points } \\
\text { with common characteristics. Cluster analysis, } \\
\text { in combination with other methods, can help } \\
\text { explain why elements cluster in certain ways } \\
\text { and not others, and what the underlying } \\
\text { causes or drivers of similarity across } \\
\text { elements are. }\end{array}$ & $\begin{array}{l}\text { Key introductory text } \\
\text { Kassambara } 2017 \\
\text { Applications to SES } \\
\text { Raudsepp-Hearne, Peterson, and } \\
\text { Bennett 2010; } \\
\text { Vackavik et al. 2013; } \\
\text { Hamann, Biggs, and Reyers 2015; } \\
\text { Meacham et al. } 2016\end{array}$ \\
\hline $\begin{array}{l}\text { Regression } \\
\text { trees }\end{array}$ & $\begin{array}{l}\text { A regression tree is a model that relates a } \\
\text { response from a variable to predictors by } \\
\text { going through a series of recursive binary } \\
\text { splits (the branches of the tree). }\end{array}$ & $\begin{array}{l}\text { Key introductory texts } \\
\text { Elith, Leathwick, and Hastie 2008; } \\
\text { Kuhn and Johnson } 2013 \\
\text { Applications to SES } \\
\text { Jouffray et al. } 2015,2019 ; \\
\text { Curtis et al. } 2018\end{array}$ \\
\hline $\begin{array}{l}\text { Neural } \\
\text { networks }\end{array}$ & $\begin{array}{l}\text { Neural networks are Bayesian regressions } \\
\text { that use a fitness function to assess their } \\
\text { performance. Recursively, it learns how to } \\
\text { best capture features of the data and become } \\
\text { good at predicting them. Application } \\
\text { examples include image and sound } \\
\text { recognition. }\end{array}$ & $\begin{array}{l}\text { Key introductory texts } \\
\text { Chollet 2017; } \\
\text { Chollet and Allaire } 2018 \\
\text { Applications to SES } \\
\text { Naik, Raskar, and Hidalgo 2016; } \\
\text { Naik et al. 2017; } \\
\text { Fairbrass et al. } 2018\end{array}$ \\
\hline $\begin{array}{l}\text { Sentiment } \\
\text { analysis }\end{array}$ & $\begin{array}{l}\text { Sentiment analysis is a supervised } \\
\text { method - humans perform part of the data } \\
\text { classification. It uses dictionaries of words } \\
\text { related to emotions and scores large } \\
\text { amounts of text, allowing one to detect } \\
\text { overall sentiments or how sentiments change } \\
\text { over time. }\end{array}$ & $\begin{array}{l}\text { Key introductory text } \\
\text { Silge and Robinson } 2017 \\
\text { Applications to SES } \\
\text { Dodds et al. 2011, 2015; } \\
\text { Spaiser et al. 2014; } \\
\text { Vosoughi, Roy, and Aral } 2018\end{array}$ \\
\hline Topic models & $\begin{array}{l}\text { Topic models allow one to describe large } \\
\text { amounts of text and classify the texts by } \\
\text { topics that better represent them. It is an } \\
\text { unsupervised method - there is no human } \\
\text { classification involved, nor is there any bias. } \\
\text { One can see how much of a topic is } \\
\text { represented in a document, or how it } \\
\text { changes over time. }\end{array}$ & $\begin{array}{l}\text { Key introductory texts } \\
\text { Blei 2012; } \\
\text { Silge and Robinson } 2017 \\
\text { Applications to SES } \\
\text { Daume, Albert, and Von } \\
\text { Gadow 2014a; } \\
\text { Rocha et al. } 2015\end{array}$ \\
\hline
\end{tabular}




\section{Case study 17.1: Using Twitter to detect invasive species}

Inspired by successful applications of data mining of social media to monitor and predict the spread of epidemic diseases, similar applications have been advocated to obtain early warnings for critical changes in SES (Galaz et al. 2010). Daume, Albert and Von Gadow (2014b), Daume (2016), and Daume and Galaz (2016) focused on the real-time nature of social media and its capacity to deliver early warnings for environmental changes in the form of species observations. This was a global study, but Twitter adoption is biased towards Europe, North America and English-speaking countries. Invasive alien species - species not native to a specific location - were chosen as an example since they are known drivers and indicators of ecosystem change with potentially significant ecological, economic and health impacts (Daume 2016).

The study focused on mentions of three invasive alien species in the northern hemisphere - grey squirrel, emerald ash borer and oak processionary moth - on Twitter. These species represent invasive alien species with different geographies, impacts and invasion stages. Twitter was queried for keywords that indicated potential direct or indirect references to these species (Daume 2016). Data collection was facilitated via the Twitter Search application programming interface (API), a public web interface that returns a sample of Tweets matching the specified search terms. The API only returns Tweets dating back at most nine days. In order to assemble a dataset covering a longer period, a web-based tool was implemented in the Java programming language, which could be run automatically and continuously. The data were then processed and analysed using a combination of bespoke tools programmed in Java and $\mathrm{R}$.

The results confirmed Twitter as a rich source of biodiversity information on various species. Primary observations of the example invasive alien species could be identified in Tweets, but the quality and completeness of this information varied. While images or videos are often included and allow an assessment of the observations, precise geolocation information is rare. At the same time, studies showed that mining Twitter uncovers observations that could not have been gathered in traditional monitoring programmes and can thus complement these. In the case of invasive alien species, even singular observations could be crucial for early detection (Daume 2016).

A key finding was that online conversations frequently emerge around Tweets related to species observation. These conversations led to the formation of ad hoc communities that together determined the name of the observed species (Daume and Galaz 2016). Given that Twitter is both a data source and a communication channel, Tweets can be viewed as an interactive data source, where the data can be actively complemented (e.g. in the case of missing geolocation information). Twitter as a data source is unique in that the gathered Tweets provide not only insights into ecological properties (i.e. species observations) but also social perspectives ranging from an implicit representation of stakeholders and their background to perceptions and sentiments on topics such as invasive species (Daume, Albert, and Von Gadow 2014b). Twitter and similar social media sources can thus be of interest not only in SES research addressing early warnings and long-term biodiversity 
observations but also for quick thematic assessments and an understanding of public perceptions.

Studies using Twitter data are bound by the Twitter rules and policies. Those forbid the general sharing of the complete data (i.e. all Tweet information collected by a study). Only the identifiers of Tweets may, with certain restrictions, be shared publicly and would then have to be 'rehydrated' using the Twitter API. This presents a potential limitation with regard to the reproducibility of a study: Tweets published by Twitter users who have closed or protected their accounts since the data was originally collected, for example, would no longer be retrievable, thus potentially leading to different results. Figure 17.1 presents a high-level typology of Tweets collected for invasive alien species monitoring.

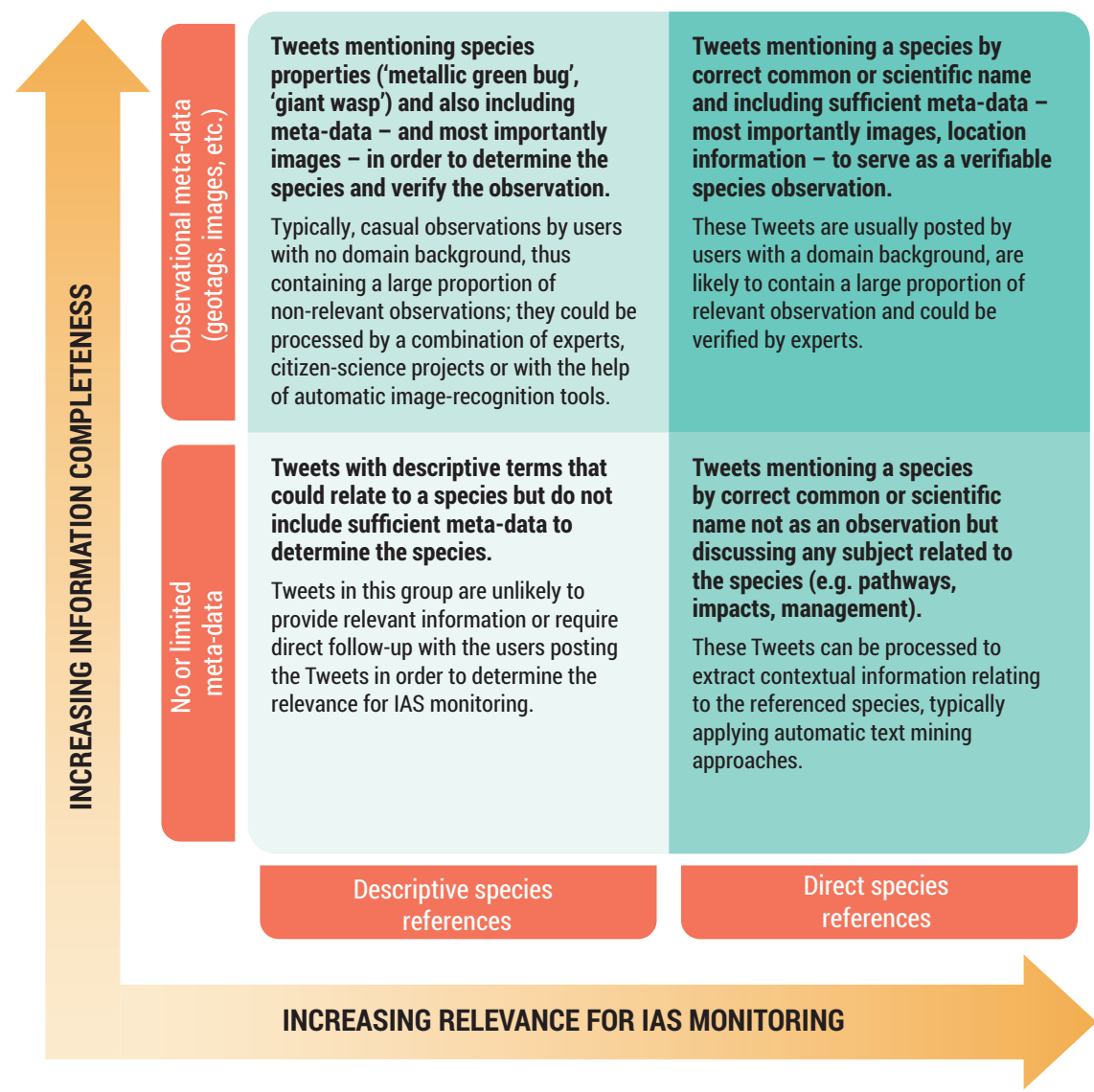

Figure 17.1 High-level typology of Tweets collected for invasive alien species monitoring (adapted from Daume 2016) 
output node predicts some aspect of interest. The intermediate layers are weights that are intended to maximise performance of a classification task (e.g. translate text, classify a picture, recognise a sound). Networks with many intermediate layers are known as deep networks. One of the most popular types is convolutional neural networks (CNN) for their performance in classifying images. Natural-language processing (NLP) is another field of artificial intelligence (computer science and linguistics) dealing with the interaction between computers and human (natural) languages. There are many methods that fall within natural-language processing. Among others, Table 17.1 indicates applications of sentiment analysis (a supervised machine-learning technique) to classify the sentiment content of text, and topic modelling (an unsupervised technique) to classify large amounts of text into topics.

\section{Limitations}

The fact that data-science approaches are different from classical statistics in terms of the data-generation process implies that the analysis will have to account for potential biases. Platforms such as Twitter, Facebook, Instagram or Flickr, for example, are rich sources of data but their users may not be representative of the underlying populations about which one wants to draw conclusions. Compared with the general population, the composition of Twitter or Facebook users is generally biased with regard to economic status or certain age brackets. However, other sources of data are often lacking, so social media data may be considered a best first approximation. This was the case in a study conducted by Wood et al. (2013), trying to infer the aesthetic value and rates of visitation for natural areas. Interviews or surveys work for smallscale problems but do not scale well, e.g. to national scales or to measure millions of opinions. Being aware of data biases can prevent the misinterpretation of results and may even shed light on how to find ways to verify how biased the dataset is. Knowing that Instagram is biased towards younger populations, for example, a multiplatform assessment improved the assessment of valued landscapes in Europe (Van Zanten et al. 2016; Donahue et al. 2018).

When working with publicly available data such as NASA imagery, Google Earth or Twitter, it is worth keeping an eye on data availability policies and how they change over time. Some data services in the USA were shut down during the Trump administration, for example. Twitter might decide to change the type of content that is available or its accessibility, thereby limiting the replicability of a study. It is good practice to keep up with data availability policies and always keep data back-ups on reliable computer servers.

\section{Resource implications}

Scalable and reproducible data-mining and pattern-recognition approaches typically require knowledge of a programming language. Many applications of pattern recognition use large volumes of unstructured data that typically need to be harvested, cleaned and transformed to render them useful. This implies automation and techniques that require the mastery of data-processing tools or programming languages like $\mathrm{R}$ or Python.

If the dataset is small (fits on a computer's memory) one might be able to run something simple such as a cluster analysis routine in Microsoft Excel or other click-based programs. However, accessing data and applying state-of-the-art techniques will require an understanding of the code used by developers and modifying it according to one's own application. It is not necessary to be a computer scientist, but a basic understanding of how computers work and the language in which procedures are encoded is a must to apply machine-learning algorithms.

For many applications, researchers need to interact with application programming interfaces. These are services allowing one to access Twitter, Flickr, Instagram or Google Earth 
data, for example. Even if it is not necessary to query new streams of data, existing data might need to be pre-processed, transformed and organised in a useful form and share code that makes one's research reproducible by colleagues and peers. Popular choices of scientific computing languages include R, Python and Julia, all of which are open access, are well documented and provide many online resources to learn at one's own pace.

Besides the programming skills required to access, clean and analyse data, another key resource implication is the need for sufficient computational resources. Analyses using large datasets such as satellite imagery often cannot be performed on a personal computer and require whole clusters of computers provided through universities or commercial cloud providers. Given the amount of data required in machine-learning applications, parallel processing may be needed. Access to, and familiarity with, the facilities for running computations remotely are therefore key requirements in data-mining and pattern-recognition research.

\section{New directions}

Opportunities for applying pattern-detection techniques to better understand SES are substantial and growing. A number of trends and potential emerging applications can be identified. Studies using the clustering of ecosystem services sets to identify and classify SES have been confined to regional and national scales, but a global classification is still lacking. In addition, harmonised datasets such as the Earth Data Cube or World Bank statistics can be used to better understand changes in SES over time (Reichstein et al. 2019). Machine-learning approaches can help researchers uncover development trajectories and anomalies, or develop early-warning systems (Scheffer et al. 2009) to monitor the unfolding of SES regime shifts or transformations.

A key challenge in SES research is to distinguish when sustainable solutions, such as poverty-reduction policies or agricultural innovations, work, and where. Data-mining and machine-learning approaches can help discover types of SES where particular solutions work and where similar SES that may benefit from these approaches are located.

Advances in text mining and language processing can be used to do more rigorous literature reviews by mapping who collaborates with whom, and to scope research opportunities or priorities. These techniques can also empower an emergent field of research in assessing aesthetic and cultural ecosystem service values over time and space at larger scales than were possible before the advent of social media data.

Machine-learning methods are no longer the luxury of computer giants. Today one can run machine-learning experiments on a regular computer or by using cloud services, which makes the methods accessible to students and low-budget research groups.

\section{Key readings}

Chollet, F. 2017. Deep Learning with Python. New York: Manning.

Chollet, F., and J.J. Allaire. 2018. Deep Learning with R. New York: Manning.

Mitchell, M. 2019. Artificial intelligence: A guide for thinking humans. London: Pelican Books.

Pearl, J., and D. Mackenzie. 2018. The Book of Why: The New Science of Cause and Effect. London: Penguin.

Wickham, H., and G. Grolemund. 2017. R for Data Science. Beijing: O’Reilly.

\section{Acknowledgements}

This chapter benefited from the careful reading and constructive feedback of Maike Hamann, as well as input ideas from Emma Sundström and Garry Peterson. Juan C. Rocha was supported by FORMAS grant 942-2015-731. 


\section{References}

Blei, D. 2012. 'Probabilistic Topic Models.' Communications of the ACM 55: 77-84.

Chollet, F. 2017. Deep Learning with Python. New York: Manning.

Chollet, F., and J.J. Allaire. 2018. Deep Learning with R. New York: Manning.

Curtis, P.G., C.M. Slay, N.L. Harris, A. Tyukavina, and M.C. Hansen. 2018. 'Classifying Drivers of Global Forest Loss.' Science 361(6407). doi:10.1126/science.aau3445.

Daume, S. 2016. 'Mining Twitter to Monitor Invasive Alien Species - An Analytical Framework and Sample Information Topologies.' Ecological Informatics 31: 70-82. doi:10.1016/j.ecoinf.2015.11.014.

Daume, S., M. Albert, and K. von Gadow. 2014a. 'Assessing Citizen Science Opportunities in Forest Monitoring Using Probabilistic Topic Modelling.' Forest Ecosystems 1(1). doi:10.1186/ s40663-014-0011-6.

Daume, S., M. Albert, and K. von Gadow. 2014b. 'Forest Monitoring and Social Media - Complementary Data Sources for Ecosystem Surveillance?' Forest Ecology and Management 316: 9-20. doi:10.1016/j.foreco.2013.09.004.

Daume, S., and V. Galaz. 2016. "Anyone Know What Species This Is?” - Twitter Conversations as Embryonic Citizen Science Communities.' PLoS ONE 11(3). doi:10.1371/journal.pone.0151387.

Dodds, P.S., E.M. Clark, S. Desu, M.R. Frank, A.J. Reagan, J.R. Williams, L. Mitchell et al. 2015. 'Human Language Reveals a Universal Positivity Bias.' Proceedings of the National Academy of Sciences 112(8): 2389-2394. doi:10.1073/pnas.1411678112.

Dodds, P.S., K.D. Harris, I.M. Kloumann, C.A. Bliss, and C.M. Danforth. 2011. 'Temporal Patterns of Happiness and Information in a Global Social Network: Hedonometrics and Twitter.' PLoS ONE 6(12): e26752. doi:10.1371/journal.pone.0026752.

Donahue, M.L., B.L. Keeler, S.A. Wood, D.M. Fisher, Z.A. Hamstead, and T. McPhearson. 2018. 'Using Social Media to Understand Drivers of Urban Park Visitation in the Twin Cities, MN.' Landscape and Urban Planning 175: 1-10. doi:10.1016/j.landurbplan.2018.02.006.

Donovan, M.K., A.M. Friedlander, J. Lecky, J-B. Jouffray, G.J. Williams, L.M. Wedding, L.B. Crowder et al. 2018. 'Combining Fish and Benthic Communities into Multiple Regimes Reveals Complex Reef Dynamics.' Scientific Reports 8(1). doi:10.1038/s41598-018-35057-4.

Elith, J., J.R. Leathwick, and T. Hastie. 2008. 'A Working Guide to Boosted Regression Trees.' Journal of Animal Ecology 77: 802-813.

Ellis, E.C., K.K. Goldewijk, S. Siebert, D. Lightman, and N. Ramankutty. 2010. 'Anthropogenic Transformation of the Biomes, 1700 to 2000.' Global Ecology and Biogeography 19(5): 589-606. doi:10.1111/j.1466-8238.2010.00540.x.

Ellis, E.C., and N. Ramankutty. 2008. 'Putting People in the Map: Anthropogenic Biomes of the World.' Frontiers in Ecology and the Environment 6(10). doi:10.1890/070062.

Fairbrass, A.J., M. Firman, C. Williams, G.J. Brostow, H. Titheridge, and K.E. Jones. 2018. 'CityNet Deep Learning Tools for Urban Ecoacoustic Assessment.' Methods in Ecology and Evolution 4(2): 206-197. doi:10.1111/2041-210X.13114.

Foley, J.A., R. DeFries, G.P. Asner, C. Barford, G. Bonan, S.R. Carpenter, F.S. Chapin et al. 2005. 'Global Consequences of Land Use.' Science 309(5734): 570-574. doi:10.1126/science.1111772.

Galaz, V., B. Crona, T. Daw, Ö. Bodin, M. Nyström, and P. Olsson. 2010. 'Can Web Crawlers Revolutionize Ecological Monitoring?’ Frontiers in Ecology and the Environment 8(2): 99-104. doi:10.1890/070204.

Hamann, M., R. Biggs, and B. Reyers. 2015. 'Mapping Social-Ecological Systems: Identifying "Green-loop" and "Red-loop" Dynamics Based on Characteristic Bundles of Ecosystem Service Use.' Global Environmental Change 34: 218-226. doi:10.1016/j.gloenvcha.2015.07.008.

Holland, J.H. 2012. Signals and Boundaries. Cambridge: MIT Press.

Jean, N., M. Burke, M. Xie, W.M. Davis, D.B. Lobell, and S. Ermon. 2016. 'Combining Satellite Imagery and Machine Learning to Predict Poverty.' Science 353(6301): 790-794. doi:10.1126/science.aaf7894.

Jouffray, J-B., M. Nyström, A.V. Norström, I.D. Williams, L.M. Wedding, J.N. Kittinger, and G.J. Williams. 2015. 'Identifying Multiple Coral Reef Regimes and Their Drivers Across the Hawaiian Archipelago.' Biological Sciences 370(1659). doi:10.1098/rstb.2013.0268.

Jouffray, J-B., L.M. Wedding, A.V. Norström, M.K. Donovan, G.J. Williams, L.B. Crowder, A.L. Erickson et al. 2019. 'Parsing Human and Biophysical Drivers of Coral Reef Regimes.' Proceedings of the Royal Society B 286(1896). doi:10.1098/rspb.2018.2544. 
Kassambara, A. 2017. Practical Guide to Cluster Analysis in R: Unsupervised Machine Learning. STHDA. Kuhn, M., and K. Johnson. 2013. Applied Predictive Modeling. New York: Springer.Meacham, M., C. Queiroz, A. Norström, and G. Peterson. 2016. 'Social-Ecological Drivers of Multiple Ecosystem Services: What Variables Explain Patterns of Ecosystem Services Across the Norrström Drainage Basin?' Ecology and Society 21(1): 14. doi:10.5751/ES-08077-210114.

Mitchell, M. 2019. Artificial Intelligence: A Guide for Thinking Humans. London: Pelican Books. Naik, N., S.D. Kominers, R. Raskar, E.L. Glaeser, and C.A. Hidalgo. 2017. 'Computer Vision Uncovers Predictors of Physical Urban Change.' Proceedings of the National Academy of Sciences 197(29). doi:10.1073/pnas.1619003114.

Naik, N., R. Raskar, and C.A. Hidalgo. 2016. 'Cities Are Physical Too: Using Computer Vision to Measure the Quality and Impact of Urban Appearance.' American Economic Review 106(5): $128-132$. doi:10.1257/aer.p20161030.

Raudsepp-Hearne, C., G.D. Peterson, and E.M. Bennett. 2010. 'Ecosystem Service Bundles for Analyzing Tradeoffs in Diverse Landscapes.' Proceedings of the National Academy of Sciences 107(11): 52425247. doi:10.1073/pnas.0907284107.

Reichstein, M., G. Camps-Valls, B. Stevens, M. Jung, J. Denzler, and N. Carvalhais. 2019. 'Deep Learning and Process Understanding for Data-Driven Earth System Science.' Nature 566(7743): 195-204. doi:10.1038/s41586-019-0912-1.

Rocha, J.C., K. Malmborg, L.J. Gordon, K.A. Brauman, and F. DeClerck. 2019. 'Mapping Social Ecological Systems Archetypes.’ Environmental Research Letters. doi:10.1088/1748-9326/ab666e.

Rocha, J.C., and R. Wikström. 2015. 'Detecting Potential Impacts on Ecosystem Services Related to Ecological Regime Shifts - A Matter of Wording.' Conference paper.

Ropero, R.F., P.A. Aguilera, and R. Rumí. 2015. 'Analysis of the Socioecological Structure and Dynamics of the Territory Using a Hybrid Bayesian Network Classifier.' Ecological Modelling 311: 73-87. doi:10.1016/j.ecolmodel.2015.05.008.

Scheffer, M., J. Bascompte, W.A. Brock, V. Brovkin, S.R. Carpenter, V. Dakos, H. Held, E.H. van Nes, M. Rietkerk, and G. Sugihara. 2009. 'Early-Warning Signals for Critical Transitions.' Nature 461(7260): 53-59. doi:10.1038/nature08227.

Silge, J., and D. Robinson. 2017. Text Mining with R. Beijing: O’Reilly.

Sonter, L.J., K.B. Watson, S.A. Wood, and T.H. Ricketts. 2016. 'Spatial and Temporal Dynamics and Value of Nature-Based Recreation, Estimated via Social Media.' PLoS ONE 11(9): e0162372. doi:10.1371/journal.pone.0162372.

Spaiser, V., T. Chadefaux, K. Donnay, F. Russmann, and D. Helbing. 2014. 'Social Media and Regime Change: The Strategic Use of Twitter in the 2011-12 Russian Protests.' SSRN Electronic Journal November. doi:10.2139/ssrn.2528102.

Surendran, N.S., B.L. Preston, A.W. King, and R. Mei. 2016. 'Using Landscape Typologies to Model Socioecological Systems: Application to Agriculture of the United States Gulf Coast.' Environmental Modelling \& Software 79: 85-95.

Václavík, T., S. Lautenbach, T. Kuemmerle, and R. Seppelt. 2013. 'Mapping Global Land System Archetypes.' Global Environmental Change - Human and Policy Dimensions 23(6): 1637-1647. doi:10.1016/j.gloenvcha.2013.09.004.

VanderPlas, J. 2016. Python Data Science Handbook. Beijing: O’Reilly.

Van Zanten, B.T., D.B. van Berkel, R.K. Meentemeyer, J.W. Smith, K.F. Tieskens, and P.H. Verburg. 2016. 'Continental-scale Quantification of Landscape Values Using Social Media Data.' Proceedings of the National Academy of Sciences, October. doi:10.1073/pnas.1614158113.

Verbesselt, J., N. Umlauf, M. Hirota, M. Holmgren, E.H. van Nes, M. Herold, A. Zeileis, and M. Scheffer. 2016. 'Remotely Sensed Resilience of Tropical Forests.' Nature Climate Change 6(11): 1028-1031. doi:10.1038/nclimate3108.

Vosoughi, S., D. Roy, and S. Aral. 2018. 'The Spread of True and False News Online.' Science 359(6380): 1146-1151. doi:10.1126/science.aap9559.

Wickham, H., and G. Grolemund. 2017. R for Data Science. Beijing: O’Reilly.

Wilson, G., J. Bryan, K. Cranston, J. Kitzes, L. Nederbragt, and T.K. Teal. 2017. 'Good Enough Practices in Scientific Computing.' PLoS Computational Biology 13(6): e1005510. doi:10.1371/journal. pcbi.1005510.

Wood, S.A., A.D. Guerry, J.M. Silver, and M. Lacayo. 2013. 'Using Social Media to Quantify Nature-based Tourism and Recreation.' Scientific Reports 3(1): 17. doi:10.1038/srep02976. 